\title{
REFLEXIONES EN TORNO \\ A LA ÚLTIMA ACTUALIZACIÓN \\ DEL DERECHO AL OLVIDO DIGITAL
}

ÁNGEL COBACHO LÓPEZ 
SUMARIO

1. INTRODUCCIÓN: EL EJERCICIO DE LOS DERECHOS FUNDAMENTALES EN LA ERA TECNOLÓGICA. 2. EL DERECHO AL OLVIDO EN EL DERECHO ESPAÑOL Y EN EL NUEVO MARCO COMUNITARIO. 2. 1. El encuadre jurídico del derecho al olvido. 2.2. La AEPD y el derecho al olvido. 3. LOS DIVERSOS ÁMBITOS DE APLICACIÓN DEL DERECHO AL OLVIDO. 3.1. El derecho al olvido y los buscadores y hemerotecas digitales. 3.2. El derecho al olvido y las redes sociales. 4. CONCLUSIONES. 5. BIBLIOGRAFÍA 


\title{
REFLEXIONES EN TORNO A LA ÚLTIMA ACTUALIZACIÓN DEL DERECHO AL OLVIDO DIGITAL
}

\author{
ÁNGEL COBACHO LÓPEZ \\ Profesor Contratado Doctor de Derecho Constitucional \\ Universidad de Murcia
}

\section{INTRODUCCIÓN: EL EJERCICIO DE LOS DERECHOS FUNDAMENTALES EN LA ERA TECNOLÓGICA}

Cuando, hace solamente cuatro años, se empezó a pensar y a escribir sobre el llamado derecho al olvido, muchos fuimos los autores que apuntamos que aquel neoderecho tendría una repercusión y un alcance solo asimilable a la dificultad real de ponerlo en práctica ${ }^{2}$. En aquellos momentos no se trataba más que de una figura que encarnaba la pretensión de cada día más ciudadanos: desaparecer de Internet, borrar todo rastro de nuestro paso por la red, sobre todo aquel cuya presencia fuera delatora de noticias o informaciones que colisionaran con nuestros intereses o con nuestros derechos. En su génesis, el ejercicio del derecho al olvido, aún no positivizado, pudo llevarse a cabo de forma soterrada por medio de los vigentes derechos de acceso, rectificación, cancelación y oposición, pero su enérgica reivindicación ponía de manifiesto que había una demanda latente de regular el ejercicio de esos mismos derechos, que, con la rápida expansión y los muchos rostros de Internet, habían sido reformulados.

Hoy en día, sin embargo, la situación es distinta. En primer lugar, porque el derecho al olvido ya existe en un texto legal: el art. 17 del Reglamento 2016/679, del Parlamento Europeo y del Consejo, de 27 de abril de 2016 (en adelante, RGPD), que derogó la Directiva 95/46/CE, y que entró en vigor el 25 de mayo de 2018,

${ }^{1}$ Facultad de Derecho, Universidad de Murcia, C/Santo Cristo, 1, 30001, Murcia. Email: acobacho@um.es

${ }^{2}$ Cfr., por todos, Simón Castellano, P. (2012), El régimen constitucional del derecho al olvido, Valencia, Tirant Lo Blanch; así como mi primera publicación sobre el particular: Cobacho López, Á. (2013), «La ponderación de bienes en los conflictos jurídicos relacionados con internet: el derecho al olvido», Desafíos para los derechos de la persona ante el siglo XXI: internet y nuevas tecnologías, Pamplona, Aranzadi. 
reconoce el derecho al olvido y regula su ejercicio; pero, además, debido a un segundo factor: las nuevas tecnologías — que ya, más que nuevas, son tecnologías en constante proceso de renovación - propician nuevos modelos de convivencia en una sociedad formada por individuos que no conciben sus relaciones interpersonales sin la intermediación de dispositivos y aplicaciones, no siempre de fácil encaje en el marco establecido por nuestro sistema jurídico, y que suponen un desafío continuo para la labor de jueces y legisladores, compelidos, de tal modo, a una labor de constante formación y actualización destinada a evitar la elaboración o aplicación extemporánea de un Derecho cuya facilidad para quedar obsoleto es cada vez mayor en plazos cada vez más breves.

Asistimos a una vertiginosa proliferación de herramientas tecnológicas que alteran nuestra forma de concebir nuestras relaciones sociales e incluso, en ocasiones, el modo en el que percibimos la realidad ${ }^{3}$. El Derecho no puede ni debe permanecer ajeno a un escenario en el cual comienzan a darse formas inéditas hasta el momento de lesión de bienes jurídicos ${ }^{4}$, ni tampoco es prudente que aborde semejantes cuestiones desde fórmulas que tal vez dieron resultado en el pasado - y que quizá por ello nos proporcionen en la actualidad cierta sensación de seguridad-, pero que en la práctica se muestran ineficaces. Tan equivocada es, a nuestro juicio, la postura de aquellos que se aferran al pasado para afrontar el presente, como la de aquellos otros que proponen planteamientos de ciencia ficción desde un futuro que aún no conocemos. Más que nunca, hoy, en la era de los cambios sociales que tanto tienen que ver con las tecnologías de la información y de la comunicación, el Derecho tiene que ir de la mano de un serio análisis sobre el hombre que lo produce. Si no entendemos al hombre de hoy, no entenderemos el Derecho que regula y ordena sus relaciones sociales.

Baste un ejemplo para ilustrar lo dicho, en relación precisamente con el ejercicio del derecho al olvido. Aunque más adelante incidiremos sobre el particular, Internet ha cambiado las reglas del juego en lo que hace referencia a la memoria y al olvido. En el ser humano, el olvido siempre ha sido un mecanismo de defensa frente a la acumulación innecesaria e inservible de datos. Las personas olvidamos muchos más datos de los que recordamos, aunque es obvio que no somos conscientes del proceso. Sin embargo, con la irrupción de Internet, la frágil memoria huma-

${ }^{3}$ Pueden, al respecto, consultarse las siguientes obras: Carr, R. (2017). ¿Qué está haciendo Internet con nuestras mentes? Superficiales, Barcelona, Taurus; Spitzer, M. (2013). Demencia digit@l, Barcelona, Ediciones B; o esta reciente entrevista: https://elpais.com/tecnologia/2018/04/24/ actualidad/1524577831_486816.html (última consulta el 1 de mayo de 2018). Cada día son más las obras que alertan de este cambio de paradigma digital.

4 Tal y como prueba la proliferación de delitos y conductas potencialmente lesivas de nuevo cuño, designados habitualmente con neologismos que ponen de manifiesto lo inédito del nuevo escenario: childgrooming, sexting, stalking, phising, pharming... Para una reflexión crítica al respecto, vid. Touriño, A. (2014). El derecho al olvido y a la intimidad en Internet, Madrid, Catarata, pp. 95-107. 
na va camino de ser sustituida por la poderosa memoria digital ${ }^{5}$. En Internet, al contrario de lo que ocurre en los humanos, la memoria es la regla; el olvido, la excepción. Internet lo preserva todo, y todo lo convierte en presente continuo: errores del pasado, escritos, fotos o vídeos — datos personales y noticias relacionadas con nosotros- de los que quisiéramos renegar ${ }^{6}$. La reedición digital de la teoría del eterno retorno es problemática y fuente de conflicto, pues donde no se olvida poco lugar queda para el perdón, y sin perdón el alcance de la ofensa termina por exceder incluso la misma intención del agresor bajo la forma del rencor ${ }^{7}$.

Internet - a partir sobre todo de la creación de la Internet 2.0, entendida como espacio horizontal de convivencia - se erige, así, en el gran panóptico digital ${ }^{8}$ en el que, revestidos de un cierto anonimato más o menos evidente, todos lo vemos todo en un presente omnicomprensivo. En paralelo, vamos despojándonos de la posibilidad de renunciar a un pasado que nos sigue como la sombra persigue al que la proyecta o, en palabras de Mayer-Schönberger, como un tatuaje fijado en el cuerpo ${ }^{9}$, ya que en la red, por defecto, se produce la conservación de la información, mientras que su cancelación o borrado efectivo sólo se produce cuando el usuario que, en su día, la introdujo, realiza los pasos tendentes a su eliminación ${ }^{10}$.

Mucho se ha escrito y reflexionado en torno a estas consideraciones, pero lo que es obvio es que estamos ante un cambio de paradigma conformado por muchos pequeños cambios que alimentan la sensación de velocidad en el proceso. «Cuando patinamos sobre hielo quebradizo, nuestra seguridad depende de nuestra velocidad» fue la cita de Ralph W. Emerson que escogió el sociólogo Zygmunt Bauman para encabezar su obra Vida líquida ${ }^{11}$. En nuestra cultura, la velocidad es un valor positivo en sí, y contrasta con un sistema jurídico de producción de normas y de solución de conflictos que sufre demoras y que, incluso cuando sigue los cauces procedimentales fijados, se muestra en ocasiones torpe y lento a la hora de dar respuesta a estas nuevas formas de conflicto.

5 Cfr. Simón Castellano, P. (2012). «El derecho al olvido en el universo 2.0». Textos universitaris de biblioteconomia i documentació, núm. 28, p. 1.

${ }^{6}$ Cfr. De Terwagne, C. (2012). «Privacidad en Internet y el derecho a ser olvidado/derecho al olvido». Revista de Internet, Derecho y Política, núm. 13, p. 54.

7 Cfr. Marín Pedreño, H. (2010). Teoría de la cordura y de los hábitos del corazón, Valencia, Pre-Textos, pp. 233-238.

${ }^{8}$ La reformulación del panóptico de Bentham se la debemos a Han, B.-Ch. (2013). La sociedad de la transparencia, Barcelona, Herder, pp. 87-95; el mismo autor usa la expresión «Big brother amable» en su libro Psicopolítica (2014), Barcelona, Herder, pp. 59-64. Bauman se ocupa de la cuestión de lo que él denomina «post-panóptico» con su particular y lúcida visión en Bauman, Z. y Lyon, D. (2013). Vigilancia líquida, Barcelona, Paidós.

9 Cfr. Mayer-Schönberger, V. (2009). Delete: The Virtue of forgetting in the Digital Age, Princeton, Princeton University Press, p. 2.

${ }^{10}$ Cfr. Simón Castellano, P. (2015). El reconocimiento del derecho al olvido digital en España y en la UE. Efectos tras la sentencia del TJUE de mayo de 2014, Barcelona, Bosch, p. 25.

11 Bauman, Z. (2010). Vida líquida, Barcelona, Paidós, p. 9. 
No es ya sólo, como apuntó Mayer-Schönberger, que Internet y las principales empresas que operan en ella hayan terminado sabiendo más sobre nosotros que nosotros mismos ${ }^{12}$, sino que está suponiendo un auténtico cambio antropológico ${ }^{13}$, en cuyo seno, necesariamente, tendrá que producirse una reforma de las leyes que regulan el ejercicio de numerosos derechos subjetivos, así como de las instituciones básicas de cualquier democracia. Desde luego, los derechos a la intimidad, honor y propia imagen han sufrido modulaciones en su ejercicio, pero ¿a qué derecho no ha alcanzado la onda expansiva de la entrada en escena de las nuevas tecnologías? Libertad de expresión, de reunión, de enseñanza... se han visto afectadas por el empleo de Internet en su ejercicio. Y, en otro plano más profundo, si el desenvolvimiento en entornos virtuales acaba por modificar a la persona que los frecuenta, ningún derecho se concibe ni ejercita igual que antes de Internet, pues la configuración biosocial de los titulares de dichos derechos, actualmente, no es la misma que hace unos años.

Se hace necesario, por tanto, repensar el adagio «ubi societas, ibi ius» ${ }^{14}$, y pensar en la evolución y adaptación del Derecho y de sus mecanismos de defensa, protección, tutela y preservación de los derechos e intereses de sus titulares a la luz del nuevo modelo social que se está gestando, pues la interacción entre Derecho y tecnología es de los fenómenos más relevantes en nuestra cultura ${ }^{15}$. Este proceso, necesariamente y como ya se ha señalado en repetidas ocasiones, habrá de estar sostenido sobre un adecuado equilibrio entre la naturaleza abierta de Internet y la protección de la privaci$\mathrm{dad}^{16}$.

A todos estos factores es necesario sumar el hecho de que las épocas de cambios rápidos o bruscos suelen suponer un alto coste para determinados colectivos de ciudadanos, sobre todo para aquellos que, por sus circunstancias personales, puedan resultar más débiles o vulnerables. En este caso habrá que prestar especial atención a los menores de edad, conocidos ya con el apelativo de nativos digitales, víctimas en muchos casos de nuevas formas de agresión y violencia ejercidas a través de medios tecnológicos, pero sobre todo de un exacerbado y, a la luz de los acontecimientos,

${ }^{12}$ Cfr. Mayer-Schönberger, V., Delete..., cit., p. 7.

13 Harari, Y. N. (2016). Homo Deus. Breve Historia del mañana, Barcelona, Debate. El autor realiza una prospectiva en cuanto a autoconsciencia y a relaciones con los demás y con el mundo a través de la tecnología, a partir de los avances con los que ya contamos y aquellos que, presumiblemente, se producirán en un no demasiado extenso período de tiempo. Va un poco más allá aún Diéguez, que aborda cuestiones ya sobre la mesa como el biomejoramiento humano o el vencimiento de los límites naturales del ser humano a través de la tecnología (cfr. Diéguez, A. [2017]. Transhumanismo. La búsqueda tecnológica del mejoramiento bumano, Barcelona, Herder).

${ }^{14}$ Cabría plantearse si es posible la existencia de un verdadero locus para una sociedad líquida formada por individuos con identidades líquidas. Si la sociedad no está en ningún sitio y en varios a la vez, ¿cómo situar o fijar una idea de justicia que dé soporte al Derecho que en ella ha de inspirarse?

${ }^{15}$ Cfr. Sanz Larruga, F. J. (1997). «El derecho ante las nuevas tecnologías de la información». Anuario da Facultade de Direito da Universidade da Coruña, núm. 1, p. 499.

${ }^{16}$ Cfr. Noval Lamas, J. (2012). «Algunas consideraciones sobre la futura regulación del derecho al olvido». Revista de Contratación Electrónica, núm. 9, p. 28. 
ingenuo, peligroso y poco realista optimismo acerca del uso de los nuevos dispositivos y de las muchas aplicaciones concebidas, al menos en teoría, para servir a nuestros intereses y facilitar nuestra existencia ${ }^{17}$.

Este trabajo se dirige a ofrecer una visión crítica acerca del derecho al olvido, como manifestación paradigmática del replanteamiento del Derecho al que nos obligan las nuevas tecnologías. La memoria digital puede erigirse en una suerte de un monstruo al que diariamente alimentamos de datos personales, propios o de terceros, y cuyos estragos, a juzgar por la inconsciencia de la que muchos usuarios hacen gala, un amplio sector de la población prefiere no prever. Como le sucedía a Funes el Memorioso, aquel personaje de Borges, la memoria de Internet se está convirtiendo en un vaciadero de basuras, y ya, a día de hoy, más recuerdos tiene Internet que los que habrán tenido todos los hombres desde que el mundo es mundo ${ }^{18}$.

\section{EL DERECHO AL OLVIDO EN EL DERECHO ESPAÑOL Y EN EL NUEVO MARCO NORMATIVO COMUNITARIO}

\subsection{El encuadre jurídico del derecho al olvido}

Antes de proseguir, convendría ofrecer una definición válida de lo que entendemos por derecho al olvido. La Agencia Española de Protección de Datos (en adelante, AEPD) lo define como «la manifestación de los tradicionales derechos de cancelación y oposición aplicados a los buscadores de Internet». Y prosigue: «el «derecho al olvido» hace referencia al derecho a impedir la difusión de información personal a través de Internet cuando su publicación no cumple los requisitos de adecuación y pertinencia previstos en la normativa. En concreto, incluye el derecho a limitar la difusión universal e indiscriminada de datos personales en los buscadores generales cuando la información es obsoleta o ya no tiene relevancia ni interés público, aunque la publicación original sea legítima (en el caso de boletines oficiales o informaciones amparadas por las libertades de expresión o de información)» ${ }^{19}$. En cualquier caso, el derecho al olvido se referiría siempre al olvido ajeno. En el mundo anglosajón, de

17 Puede, al respecto, consultarse el trabajo: Cobacho López, Á. (2013). «Autodeterminación informativa de los menores II», en Pérez Álvarez, S., Burguera Ameave, L. y Paul Larrañaga, K., Menores e Internet, Pamplona, Thomson-Reuters Aranzadi, pp. 343-366. En general, toda la obra se refiere a los principales peligros reales que entraña el uso de Internet y las nuevas tecnologías por los menores. Algunos datos recientes son motivo suficiente como para dar la voz de alarma, por el riesgo que suponen y porque, además, constituyen infracciones a la normativa española en materia de cesión de datos por parte de menores de edad. Al respecto, cfr. http://www.abc.es/familia/educacion/abci-72-por-cientoninos-espanoles-entre-6-y-11-anos-tiene-perfil-alguna-social-201804061642_noticia.html (última consulta el 1 de mayo de 2018).

18 Borges, J. L. (2006). Ficciones, Madrid, Alianza Editorial.

19 http://www.agpd.es/portalwebAGPD/CanalDelCiudadano/derecho_olvido/index-ides-idphp. php (última consulta el 26 de abril de 2018). 
hecho, se alude en su misma enunciación, de manera implícita, a la tercera persona de la que se solicita el olvido, al hablar en voz pasiva del derecho a ser olvidado (right to be forgotten).

Una vez despejadas en sentido positivo, por la STC 292/2000 ${ }^{20}$, las dudas concernientes a la consideración del derecho reconocido en el art. 18.4 CE como derecho fundamental autónomo, distinto del genérico derecho al honor, intimidad personal y familiar y propia imagen a que se refiere el art. 18.1 CE, parece obvio que este derecho a la protección de datos, o de autodeterminación normativa, es el seno idóneo para ubicar un posible anclaje constitucional del derecho al olvido ${ }^{21}$. No obstante, el art. $18 \mathrm{CE}$ no es la única sede en la que puede entenderse amparado el derecho al olvido. No faltan los autores, con los que coincidimos, que apuntan a la dignidad humana y al libre desarrollo de la personalidad del art. 10.1 CE como el locus natural de este derecho ${ }^{22}$, cuyo origen se remonta al año 1997, cuando un Juzgado de primera instancia de Bruselas consideró que el derecho al olvido se inclúáa en el derecho a la vida privada consagrado en el art. 8 del Convenio Europeo de Derechos Humanos ${ }^{23}$.

El marco jurídico europeo sobre protección de datos, originariamente, estuvo encabezado por la Directiva Europea 95/46/CE del Parlamento Europeo y del Consejo, de 24 de octubre de $1995^{24}$, que constituyó el texto de referencia en materia de protección de datos personales. A través de ella se inauguró un marco normativo orientado a establecer un equilibrio entre un nivel elevado de protección de la vida privada de las personas físicas y la libre circulación de datos personales dentro de la Unión Europea. La trasposición de la Directiva en ámbito interno dio lugar a la Ley Orgánica 15/1999, de 13 de diciembre, de Protección de Datos.

Si bien es cierto que ni la Directiva comunitaria ni la LO 15/1999 se referían expresamente al derecho al olvido, también lo es que en ambas normas se consagraban principios entre los cuales tal derecho podría hallar acomodo. En particular, los principios de calidad o finalidad de los datos y de consentimiento de sus titulares, reconocidos en los artículos 4 y 6 de la Ley Orgánica 15/1999, respectivamente.

20 «[...] la singularidad del derecho a la protección de datos, pues, por un lado, su objeto es más amplio que el del derecho a la intimidad, ya que el derecho fundamental a la protección de datos extiende su garantía no sólo a la intimidad en su dimensión constitucionalmente protegida por el art. 18.1 CE, sino a lo que en ocasiones este Tribunal ha definido en términos más amplios como esfera de los bienes de la personalidad que pertenecen al ámbito de la vida privada, inextricablemente unidos al respecto de la dignidad personal [...]» (STC 292/2000, de 30 de noviembre, F.J. 6.)

${ }_{21}$ Así lo entendió también la Agencia de Seguridad de las Redes y de la Información de la Unión Europea (ENISA), en su Propuesta «The right to be forgotten - between expectations and practise», de 18 de octubre de 2012, p. 3.

${ }^{22}$ Por todos, Gomes de Andrade, N. N. (2012). «El olvido: El derecho a ser diferente... de uno mismo. Una reconsideración del derecho a ser olvidado». Revista de Internet, Derecho y Política, núm. 13 , pp. 69-71; y Simón Castellano, P. (2012). El régimen constitucional, cit., pp. 119-121.

${ }^{23}$ Cfr. Tribunal de première instance, Bruxelles, rôle 956463A.

${ }^{24}$ DO L 281 de 23 de noviembre de 1995, 31-50. 
En virtud del principio de calidad, «los datos de carácter personal objeto de tratamiento no podrán usarse para finalidades incompatibles con aquellas para las que los datos hubieran sido recogidos», y, además, dichos datos de carácter personal «serán exactos y puestos al día de forma que respondan con veracidad a la situación actual del afectado» (arts. 4.2 y 4.3 LO 15/1999); y el principio de consentimiento, por su parte, exigía que el tratamiento de datos de carácter personal requiriese el consentimiento del afectado, que podría ser revocado cuando existiera causa justificada y sin efectos retroactivos. La entonces vigente LO 15/1999 concedía igualmente al titular de los datos el derecho de oposición a su tratamiento cuando concurrieran motivos fundados y legítimos relativos a una concreta situación personal, en cuyo supuesto el responsable del fichero excluiría del tratamiento los datos relativos al afectado (cfr. art. $6 \mathrm{LO})$.

Cuando se aprobó la Directiva europea de Protección de Datos era difícil prever la enorme capacidad de almacenamiento que presentaría Internet. En 1995 la Internet 2.0 aún ni había nacido, y la red era un mero suministrador de datos de carácter vertical. Desde hacía años se había hecho necesaria una reformulación del marco normativo sobre protección de datos, que englobara entre sus disposiciones al derecho al olvido. Es por ello que, a comienzos de 2012, desde la Comisión Europea, se presentó una «Propuesta de Reglamento general de Protección de datos», de reforma de la Directiva existente, que fue, en su momento, el primer texto de ámbito europeo que contemplaba de forma explícita el derecho al olvido. Dicha propuesta, informada positivamente por el Supervisor Europeo de Protección de Datos, que la calificó como «un gran paso adelante en la protección de los datos en Europa» ${ }^{25}$, se convirtió en un texto legal hace dos años, cuando vio la luz el Reglamento (UE) 2016/679 del Parlamento Europeo y del Consejo relativo a la protección de las personas físicas en lo que respecta al tratamiento de datos personales y a la libre circulación de estos datos y por el que se deroga la Directiva 95/46/CE ${ }^{26}$.

25 SEPD, Informe de 7 de marzo de 2012 sobre el paquete legislativo de reforma de la protección de datos, en http://eur-lex.europa.eu/legal-content/ES/ALL/?uri=CELEX:52012XX0630(01) (última consulta el 26 de abril de 2018).

${ }^{26}$ Reglamento (UE) 2016/679 del Parlamento Europeo y del Consejo de 27 de abril de 2016 relativo a la protección de las personas físicas en lo que respecta al tratamiento de datos personales y a la libre circulación de estos datos y por el que se deroga la Directiva 95/46/CE (DO L 119 de 4 de mayo de 2016, 1-88). Sobre el RGPD, cfr. López Álvarez, L. F. (2016). Protección de datos personales: adaptaciones necesarias al nuevo Reglamento europeo, Madrid, Francis Lefebvre. El autor califica la nueva norma de «muy técnica y de difícil comprensión, pero al mismo tiempo necesaria y vital para el buen funcionamiento de las instituciones, públicas y privadas, en el contexto de desarrollo tecnológico en el que se encuentran inmersas. Esta regulación es más aperturista que la actual y permite nuevas posibilidades de tratamientos de datos y, en consecuencia, de beneficios económicos, siempre que las actividades se ajusten a lo que se dispone» (Ibidem, p. 9). Igualmente esencial es la consulta de la obra colectiva dirigida por Piñar Mañas, J. L. (2016). Reglamento europeo de protección de datos. Hacia un nuevo modelo europeo de privacidad, Madrid, Editorial Reus. También encontramos un buen resumen de las principales novedades del Reglamento en Crespo Vitorique, I. (2016). «El nuevo reglamento de protección de datos, ¿hacia dónde ir?: decálogo de los principales aspectos que tener en cuenta». Análisis GAEP, mayo, pp. 1-3. 
El RGPD contempla, como hacía la propuesta previa, el derecho al olvido en su art. 17, entre los derechos de los titulares de los datos objeto de tratamiento: el derecho de acceso (art. 15); el derecho de rectificación (art. 16); el derecho de cancelación o supresión (art. 17); el derecho de oposición y decisiones individuales automatizadas (art. 21); el derecho a la limitación de los datos (art. 18); y el nuevo derecho a la portabilidad de los datos (art. 20).

La nueva norma entró en vigor el 25 de mayo de 2018 en virtud de su art. 94, fecha en la que se consideró derogada la Directiva 95/46/CE. Hasta el momento de la publicación de la reciente Ley Orgánica 3/2018, de 5 de diciembre, de Protección de Datos Personales y garantía de los derechos digitales (en adelante, LOPD), la situación en la que quedó nuestra LO 15/1999 fue durante un tiempo compleja: no estaba derogada, pero sí podía entenderse normativamente desplazada desde la entrada en vigor del RGPD. El tema no fue sencillo y aconsejó que en la Sección de Derecho Público de la Comisión General de Codificación se acometiera, junto con la Agencia Española de Protección de Datos, el análisis de las implicaciones que el Reglamento debía tener en la LOPD. En cualquier caso, en algunas ocasiones nuestra vigente LOPD será el complemento nacional a que, en diversos artículos, apela el Reglamento; en otras, será de total aplicación en el caso de actividades no comprendidas en el ámbito de aplicación de la nueva normativa europea.

En el RGPD, el derecho al olvido (bajo la denominación «derecho de supresión de los datos») sigue encontrando su razón de ser en los principios de calidad (art. 5.1.d RGPD) y de finalidad de los datos (art. 5.1.b RGPD), así como en el principio de proporcionalidad (art. 5.1.c RGPD) unido al de consentimiento (art. 7 RGPD), en relación con la licitud del tratamiento (art. 6 RGPD). De todo este entramado normativo emerge el ya positivizado derecho al olvido, con el propósito de que todo dato personal disponible en Internet se adecue a la finalidad perseguida por su tratamiento y no exceda esa función, so pena de poderse provocar la solicitud de su desaparición.

En consecuencia, pese a provenir de derechos ya existentes, se puede afirmar que el derecho al olvido ha encontrado su lugar en nuestro ordenamiento, y que su reconocimiento provoca un cierto reforzamiento de la posición del ciudadano respecto al control de sus datos, a la vez que no se impide el tratamiento legítimo de esos mismos datos, necesario para el funcionamiento y desarrollo de las nuevas tecnologías y modelos de negocio basados en el Internet de las cosas o en el Big Data, entre otras innovaciones tecnológicas ${ }^{27}$.

El derecho al olvido queda diseñado, así, como un derecho de contornos precisos cuyo ejercicio se contempla para los supuestos del art. 17.1 RGPD ${ }^{28}$, ejercible frente

27 Álvarez Caro, M. (2016). «El derecho a la supresión o al olvido», en Piñar Mañas, J. L, Reglamento general..., cit., p. 255.

$28 \ll$ El interesado tendrá derecho a obtener sin dilación indebida del responsable del tratamiento la supresión de los datos personales que le conciernan, el cual estará obligado a suprimir sin dilación indebida los datos personales cuando concurra alguna de las circunstancias siguientes: a) los datos personales ya no sean necesarios en relación con los fines para los que fueron recogidos o tratados de otro 
a cualquier responsable de tratamiento de datos, ya sean motores de búsqueda, ya de otro tipo, tales como blogs, redes sociales, aplicaciones de dispositivos móviles... Los límites del derecho al olvido se enumeran en el art. 17.3 $\mathrm{RGPD}^{29}$, y están relacionados con el juicio de ponderación que merezcan los conflictos que surjan entre el derecho al olvido y otros derechos fundamentales, cuya resolución tendrá que caracterizarse por determinar, de manera justificada, qué interés debe prevalecer en cada caso; y con determinadas categorías de datos especiales que, por su singular trascendencia, no podrán ser suprimidos a solicitud del interesado. En consecuencia, será de nuevo el criterio de la ponderación de los bienes jurídicos en conflicto el que determinará la eventual prevalencia del derecho al olvido o, por el contrario, su inaplicación en virtud de intereses superiores.

\subsection{La AEPD y el derecho al olvido}

Durante años, mucho antes de la promulgación del nuevo RGPD, la AEPD fue destinataria de numerosas quejas y reclamaciones de ciudadanos que pretendían la desaparición de determinados datos personales visibles y públicos en Internet, cuya mera presencia les suponía un perjuicio. La mayor parte de esas quejas iban destinadas a que los motores de búsqueda (en la mayor parte de las ocasiones, Google), dejaran de incluir en los resultados de búsqueda informaciones que contenían datos personales, y que, a juicio de los reclamantes, afectaban a la dignidad personal, al honor, a la intimidad y a un sinfín de intereses legítimos.

En lo referente al derecho al olvido, la AEPD cambió en muy corto espacio de tiempo el criterio que adoptó cuando empezaron a planteársele reclamaciones. En diversas resoluciones de 2007 consideró que la publicación de informaciones veraces

modo; b) el interesado retire el consentimiento en que se basa el tratamiento de conformidad con el artículo 6, apartado 1, letra a), o el artículo 9, apartado 2, letra a), y este no se base en otro fundamento jurídico; c) el interesado se oponga al tratamiento con arreglo al artículo 21, apartado 1, y no prevalezcan otros motivos legítimos para el tratamiento, o el interesado se oponga al tratamiento con arreglo al artículo 21, apartado 2; d) los datos personales hayan sido tratados ilícitamente; e) los datos personales deban suprimirse para el cumplimiento de una obligación legal establecida en el Derecho de la Unión o de los Estados miembros que se aplique al responsable del tratamiento; f) los datos personales se hayan obtenido en relación con la oferta de servicios de la sociedad de la información mencionados en el artículo 8, apartado $1 »$ (art. 17.1 RGPD).

29 «Los apartados 1 y 2 no se aplicarán cuando el tratamiento sea necesario: a) para ejercer el derecho a la libertad de expresión e información; b) para el cumplimiento de una obligación legal que requiera el tratamiento de datos impuesta por el Derecho de la Unión o de los Estados miembros que se aplique al responsable del tratamiento, o para el cumplimiento de una misión realizada en interés público o en el ejercicio de poderes públicos conferidos al responsable; c) por razones de interés público en el ámbito de la salud pública de conformidad con el artículo 9, apartado 2, letras h) e i), y apartado 3; d) con fines de archivo en interés público, fines de investigación científica o histórica o fines estadísticos, de conformidad con el artículo 89, apartado 1, en la medida en que el derecho indicado en el apartado 1 pudiera hacer imposible u obstaculizar gravemente el logro de los objetivos de dicho tratamiento, o e) para la formulación, el ejercicio o la defensa de reclamaciones» (art. 17.3 RGPD). 
entraba dentro del ejercicio de las libertades informativas, y que, si existían conflictos entre estas libertades y los derechos de intimidad, honor y propia imagen, debían solventarse en la jurisdicción ordinaria. De igual modo, en lo referente a la responsabilidad concreta en el tratamiento de datos por parte de los buscadores, estimó que tampoco ellos eran responsables por la publicación de los datos personales, ya que su única labor se limitaba a localizar información en Internet, y que, en caso de exigir responsabilidades, los damnificados debían dirigirse contra los responsables de las páginas webs en las que se alojara la información, y no contra el motor de búsqueda ${ }^{30}$. Sin embargo, a partir del año $2009^{31}$, la Agencia modificó su criterio, y comenzó a dictar resoluciones que afirmaban la responsabilidad de los buscadores sobre los datos que tratan ${ }^{32}$. Esta nueva línea de actuación provocó la apertura de numerosos procedimientos contra el buscador Google, en los que le conminaba a eliminar de sus

${ }^{30}$ Cfr. Resolución TD/00299/2007, que entendía que «los buscadores tipo "Google", "Yahoo", "MSN Search", "AOL Search", etc., realizan la localización de información en Internet, en base a unos criterios que le son señalados por el usuario, buscando ocurrencias en textos o documentos publicados en la red y ofreciendo enlaces a los mismos. Así, la información no se encuentra ubicada en los servidores o máquinas de los prestadores de los servicios de búsqueda, sino en las máquinas hacia las cuales apuntan los enlaces que ofrecen los buscadores, por lo que, la cancelación de los datos, si procede, deberá ejercitarse ante los responsables de las máquinas que contienen la información».

${ }^{31}$ Afirmaba la propia AEPD en 2009: «Las solicitudes de cancelación de los datos o de oposición al tratamiento de los mismos por los buscadores de Internet, aun no siendo muy numerosas en valores absolutos, se han incrementado en un $200 \%$. Lo que revela que cada vez es mayor el interés mostrado por los ciudadanos para que no aparezcan sus datos personales en los índices que ofrecen los servicios de búsqueda en Internet a partir de los datos identificativos de una persona.» (Memoria anual de la AEPD de 2009, disponible en http://www.agpd.es/portalwebAGPD/LaAgencia/informacion_institucional/ common/memorias/2010/AEPD_Memoria_2010.pdf, p. 11, última consulta el 3 de mayo de 2018).

${ }^{32}$ Cfr., por todas, la resolución TD/01164/2008, que basa su cambio de criterio en el documento WP 148 de 4 de abril de 2008, elaborado por el Grupo de Trabajo G29. Dicho documento entendió que «Un proveedor de buscadores que trata datos de los usuarios incluyendo direcciones IP y/ o cookies permanentes que contengan un identificador único se encuentra dentro del ámbito material de la definición de responsable de tratamiento, puesto que determina de forma efectiva las finalidades y los medios del tratamiento. La naturaleza multinacional de los grandes proveedores de servicios de búsqueda (con frecuencia con oficinas principales ubicadas fuera del EEE, con servicios prestados en todo el mundo, y con la implicación de distintas sucursales y posiblemente de terceros en el tratamiento de los datos personales) ha ocasionado un debate sobre la pregunta de quién debería considerarse el responsable de tratamiento en relación con un tratamiento de datos personales. Al Grupo de Trabajo le gustaría insistir en la diferencia entre las definiciones de legislación en materia de protección de datos del EEE y la cuestión de si esta legislación se aplica en una situación determinada. Un proveedor de buscadores que efectúa el tratamiento de datos personales, como registros con historiales de búsquedas personalmente identificables, se considera el responsable de tratamiento de estos datos personales, independientemente de la cuestión acerca de la jurisdicción» (Disponible en https://www.agpd.es/portalwebAGPD/ canaldocumentacion/internacional/common/pdf/WP_148_Dictamen_Buscadores_es.pdf, última consulta el 3 de mayo de 2018). Orza Linares expone de forma brillante un análisis de esta evolución de criterios por parte de la AEPD, en Orza Linares, R. M. (2013). «El derecho al olvido en Internet: algunos intentos para su regulación legal», en Corredoira y Alfonso, L. y Cotino Hueso, L., Libertad de expresión e información en Internet. Amenazas y protección de los derechos personales, Madrid, Centro de Estudios Políticos y Constitucionales, pp. 478-487. 
resultados de búsqueda los datos que corresponden a los reclamantes, y desembocó en el recurso que presentó Google Spain S. L. ante la Audiencia Nacional, por cuanto entendió que la responsabilidad de mantener los datos personales recaía sobre los webmasters y no de los motores de búsqueda.

El procedimiento se inició cuando la Sección primera de la Sala de lo Contencioso Administrativo de la Audiencia Nacional, en el curso del procedimiento ordinario 211/2009, dictó una providencia de 22 de febrero de 2011 por la que se planteó una cuestión prejudicial de interpretación ante el Tribunal de Justicia de la Unión Europea (en adelante, TJUE), para que éste esclareciera el problema acerca de si la actividad de Google puede considerarse tratamiento de datos sometido, por tanto, a los derechos de cancelación u oposición ${ }^{33}$. Todo este procedimiento finalizó con la conocida Sentencia del TJUE de 13 de mayo de 2014, que, contra todo pronóstico, consideró a Google Spain S. L. como encargada de tratamiento de datos y, por tanto, responsable de los perjuicios que de dichos datos pudieran eventualmente derivarse ${ }^{34}$. Más adelante tendremos ocasión de comentar algún aspecto en particular de esta resolución.

En resumen, el dilema sobre el que siempre pivotaba la argumentación de la Agencia, en uno u otro sentido, consistía en calificar o no la actividad de los buscadores como tratamiento de datos personales, y, junto a esa cuestión, aclarar si la legislación europea les era aplicable y si los afectados por la publicación de datos personales podían ejercer frente a ellos los derechos de cancelación y oposición. A los tres planteamientos dio respuesta positiva la Agencia, de manera inequívoca sobre todo a partir de 2009. Además, recomendó desde sus primeras resoluciones sobre el

33 Peter Fleischer, máximo responsable de privacidad de Google, escribe al respecto en su blog personal: «There is an even more extreme end of the "right to be forgotten" spectrum, which bolds that this deletion right can be exercized not just against the publisher of the content (e.g., a newspaper website), but even against hosting platforms and other intermediaries like search engines that merely host or link to this third-party content. This view is being litigated in Spain, as the Spanish Data Protection Authority is suing Google to delete links to third-party content, like newspaper articles, that the DPA has acknowledged are legal. In other words, the $D P A$ is attempting to apply this reading of the "right to be forgotten" to delete links to content in a search engine, despite the fact that the original content is legal and will remain on the Web. Cases like this will require judicial review, since they clearly posit a conflict of two fundamental rights: privacy and the "right to be forgotten" against freedom of expression. I expect this issue to be considered at the European Court of Justice.» En http:// peterfleischer.blogspot.com/2012/01/right-to-be-forgotten-or-how-to-edit.html (última consulta el 21 de mayo de 2018).

${ }^{34}$ Las conclusiones generales (ECLI:EU:C:2013:424) que el 25 de junio de 2013, en el transcurso del proceso, presentó el abogado del TJUE Niilo Jääskinen, abogaban por eximir a Google Spain, S. L. de cualquier responsabilidad, al no considerar tratamiento de datos la actividad de los buscadores. El informe puede consultarse en http://curia.europa.eu/juris/document/document. jsf?docid=138782\&doclang=ES (última consulta el 24 de mayo de 2018). Un breve análisis de dichas conclusiones podemos encontrarlo en Azurmendi, A. (2015), «Por un «derecho al olvido» para los europeos: aportaciones jurisprudenciales de la Sentencia del Tribunal de Justicia europeo del caso Google Spain y su recepción por la Sentencia de la Audiencia Nacional española de 29 de diciembre de 2014», en Revista de Derecho Político, n. ${ }^{\circ}$ 92, enero-abril de 2015, pp. 276-279. 
particular ${ }^{35}$ que las páginas web utilizaran medidas técnicas para evitar que los datos personales cuyo tratamiento pretendiera cancelarse fueran indexados por los motores de búsqueda (con lo que suele aludir al protocolo de exclusión robots.txt ${ }^{36} \mathrm{o}$ a protocolos semejantes, que impiden que las llamadas «arañas web» o «web crawlers», mediante las que los buscadores desempeñan su función de rastreo, localicen los datos cuya cancelación u oposición se ha solicitado).

Incluso la AEPD aplicó, a partir de nuestra LO 15/1999, la teoría de los límites del derecho al olvido que luego cristalizarían en el art. 17.3 RGPD, en el sentido de excluir de su ámbito de aplicación aquellos datos que se entendieran protegidos por gozar de un estatus especial, debido, generalmente, al interés público que suscitaban o a la finalidad legítima por la que permanecían expuestos ${ }^{37}$.

En el fondo, la AEPD se limitó, a lo largo de todos estos años precedentes a la entrada en vigor de una normativa que regulara de forma expresa el derecho de supresión de datos, a resolver las quejas y reclamaciones que se le iban planteando mediante la aplicación de los principios de calidad o finalidad de los datos unido al de consentimiento, y sobre la base de los derechos de cancelación y oposición de datos. La disponibilidad de tales instrumentos bastó para elaborar todo un corpus de resoluciones y recomendaciones que convirtieron a nuestra Agencia en una pionera en materia de derecho al olvido digital ${ }^{38}$.

35 Al respecto, vid. Resolución TD/00175/2009 e Informe jurídico 0214/2010 (disponible en https://www.agpd.es/portalwebAGPD/canaldocumentacion/informes_juridicos/derecho_acceso_ rectificacion_cancelacion_oposicion/common/pdfs/2010-0214_Publicaci-oo-n-en-Diarios-Oficialesde-las-notificaciones-y-su-indexaci-oo-n-en-los-motores-de-b-uu-squeda-en-Internet.pdf, última consulta el 3 de mayo de 2018): «Al margen del requerimiento dirigido por esta Agencia al buscador Google, sería preciso que, dado que el interesado ya se ha dado por notificado de los mencionados actos administrativos, objetivo que se pretendía con su publicación en los citados diarios oficiales, por parte de la Diputación Provincial de Córdoba y la Diputación Provincial de Cádiz, se dictaran las órdenes oportunas para limitar la indexación del nombre y apellidos de Don A.A.A. en los mencionados documentos mediante la incorporación de un código (......), con objeto de que en el futuro los motores de búsqueda de Internet no puedan asociarlo al interesado» (Resolución TD/00175/2009, F.D. 11).

${ }^{36}$ El estándar de exclusión de robots, también conocido como el protocolo de la exclusión de robots o protocolo de robots.txt es un método para evitar que ciertos bots (programas informáticos que imitan el comportamiento humano) que analizan los sitios Web u otros robots que investigan todo o una parte del acceso de un sitio Web, público o privado, agreguen información innecesaria a los resultados de búsqueda.

37 Puede consultarse, sobre el derecho al olvido de los cargos públicos, Cobacho López, Á. y Burguera Ameave, L. (2013). «El derecho al olvido de los políticos en las campañas electorales», en Corredoira y Alfonso, L. y Cotino Hueso, L., Libertad de expresión..., cit., pp. 501-520.

38 Afirma al respecto Simón Castellano que «la AEPD jugó un papel clave en el ámbito europeo al reconocer la existencia del derecho al olvido digital enmarcado exclusivamente dentro de la lógica del derecho fundamental a la protección de datos, fundamentado en los principios del consentimiento y de finalidad de los datos y concretado en las facultades subjetivas de cancelación y oposición». Cfr. Simón Castellano, El reconocimiento..., cit., p. 219. 
A día de hoy, la AEPD sigue atendiendo numerosas reclamaciones relacionadas con el derecho al olvido y los derechos de cancelación y oposición, si bien el número de reclamaciones sobre el particular ya no es tan elevado ni se incrementa tan rápidamente como en años anteriores ${ }^{39}$.

\section{LOS DIVERSOS ÁMBITOS DE APLICACIÓN DEL DERECHO AL OLVIDO}

A la hora de diseñar una panorámica de aquellos entornos en los que el derecho al olvido tiene una mayor relevancia práctica, nos encontramos de entrada con dos puntos de partida diferentes. En función de ante cuál de ellos nos situemos, será distinta la naturaleza de los recursos que el Derecho pone a nuestro alcance para lograr nuestro objetivo de ser olvidados. Nos referimos a que exista o no un consentimiento previo a la cesión de los datos personales que pretendemos eliminar. Si no existió el consentimiento al tratamiento automatizado de los datos personales, la LOPD pone a disposición del usuario el derecho de oposición (art. 18); mientras que si, por el contrario, concurrió ese consentimiento que ahora se pretende revocar, el adecuado será el ejercicio de los derechos de rectificación y supresión de los datos (arts. 14 y 15, respectivamente). En el RGPD, de igual modo, el ejercicio del derecho de supresión de datos viene modulado en función de si ha concurrido o no el consentimiento del usuario que ahora pretende borrar sus datos personales de Internet.

A día de hoy, las pretensiones que involucran el derecho al olvido están usualmente relacionadas con redes sociales, motores de búsqueda y hemerotecas digitales. Como es obvio, sólo en el caso de las redes sociales es concebible la prestación del consentimiento en la cesión de los datos (si bien es igualmente cierto que también las redes sociales pueden prestarse a conductas en las cuales no exista dicho consentimiento; pensemos, por ejemplo, en conductas tales como la creación de falsos perfiles o el etiquetado en fotos por parte de terceros). A continuación, nos ocuparemos con cierto detalle de ambos supuestos, contemplados de forma expresa y diferenciada en los arts. 93 y 94 LOPD.

39 «Respecto a las consultas sobre el ejercicio de derechos por parte de los ciudadanos, destaca que más del $50 \%(53,34 \%)$ fueron sobre el derecho de cancelación, y un 26,56\% específicamente sobre el denominado «derecho al olvido». Por lo que respecta al resto de derechos, un $9,5 \%$ se plantearon sobre el derecho de oposición, el 7,92\% sobre el derecho de acceso, y únicamente un 2,68\% sobre el derecho de rectificación» (Memoria 2016 AEPD, p. 43, en http://www.agpd.es/portalwebAGPD/LaAgencia/ informacion_institucional/common/memorias/2016/Memoria_AEPD_2016.pdf, última consulta el 26 de abril de 2018). Según consta en la propia web de la AEPD, los procedimientos más relevantes en los que se ha visto involucrado el derecho al olvido son aquellos que han dado lugar a las resoluciones TD/01997/2014, TD/01955/2014, TD/01533/2014, TD/01843/2014, TD/00592/2015, TD/00594/2015, TD/00609/2015, TD/00921/2015. 


\subsection{El derecho al olvido y los buscadores y hemerotecas digitales}

Respecto a los buscadores, ya esbozamos el problema que plantean en función de si la actividad que realizan puede o no ser considerada tratamiento de datos, cuestión que quedó resuelta en la referida STJUE de 13 mayo de $2014^{40}$. Pero confluye, además, otro factor que puede complicar aún más las cosas: ¿qué sucede cuando la información que proporcionan tanto motores de búsqueda como hemerotecas online es veraz? El principio de calidad o relevancia de los datos adquiere en estos casos una importancia determinante, a la hora sobre todo de decidir qué bien jurídico debe prevalecer: si las libertades informativas o la intimidad, honor y propia imagen de los ciudadanos.

El efecto multiplicador de los buscadores, además, facilita enormemente el acceso global a las numerosas informaciones acerca de nosotros que pueden existir en Internet. De nuevo, los derechos de cancelación, rectificación y oposición, junto con el nuevo derecho de supresión de los datos personales desempeñarán, como puede fácilmente deducirse, un papel esencial, con la finalidad, si bien no de eliminar de forma radical los datos que se ofrecen, sí de procurar una ponderación justa y equilibrada de los bienes jurídicos en juego ${ }^{41}$.

Son dos las sentencias que, a nuestro parecer, mejor reflejan esta ponderación de derechos: la referida STJUE de 13 de mayo de 2014; y la STS 545/2015, de 15 de octubre (matizada posteriormente por la STC 58/2018, de 4 de junio). La primera de ellas revistió especial trascendencia, al ser la primera vez que el TJUE tuvo ocasión de pronunciarse, en este caso afirmativamente, sobre la existencia y aplicación del derecho al olvido digital.

Uno de los puntos especialmente subrayados por el Tribunal es el carácter singular de los buscadores y la afectación que su actividad produce sobre los derechos de las personas. En la sentencia se enfatizó el impacto que tiene la difusión de datos personales a través de la página de resultados de un buscador, porque se trata de una difusión global de esos datos, que dota a esa información de carácter ubicuo y que ofrece una visión estructurada de la información relativa a una persona que permite establecer un perfil más o menos detallado de ésta, lo cual provoca que se deba atender con más intensidad a los derechos de los interesados, a la hora de ponderarlos con otros intereses que entran en conflicto ${ }^{42}$.

40 Sentencia del Tribunal de Justicia de la Unión Europea, Google Spain, S.L. y Google Inc. vs. Agencia Española de Protección de Datos (AEPD) y Mario Costeja González, ECLI:EU:C:2014:317. Para un análisis pormenorizado de la sentencia, vid. Berrocal Lanzarot, A. I. (2017). Derecho de supresión de datos o derecho al olvido, Madrid, Editorial Reus, pp. 119-169; así como Azurmendi, A. (2015), «Por un «derecho al olvido» para los europeos: aportaciones jurisprudenciales de la Sentencia del Tribunal de Justicia europeo del caso Google Spain y su recepción por la Sentencia de la Audiencia Nacional española de 29 de diciembre de 2014», en Revista de Derecho Político, n. ${ }^{\circ}$ 92, enero-abril de 2015, pp. 283-292.

41 Por ejemplo, mediante la restricción de la información ofrecida, en lugar de su supresión, en caso de que dicha información pudiera revestir interés público.

42 Cfr. Mieres Mieres, L. J. (2014). El derecho al olvido digital, Madrid, Iosu Latorre, p. 44. 
El TJUE sostuvo los argumentos de la AEPD y consideró que Google utiliza de forma «automatizada, constante y sistemática» información personal, que recoge, procesa y conserva de los diferentes sitios web enlazados. Consideró la información indexada en los buscadores como un fichero de datos sobre cuya finalidad y destino decide Google. Por tanto, a la pregunta sobre si los motores de búsqueda realizan habitualmente tratamiento de datos conforme a la normativa en vigor, la respuesta fue, contra cierto sentir general y pese a las conclusiones del letrado Jääskinen, inesperadamente afirmativa ${ }^{43}$.

La importancia de esta sentencia radica en que la misma supuso dar existencia y fuerza al derecho al olvido, mientras que por otro lado abrió por primera vez la posibilidad de solicitar directamente a Google el borrado de los datos personales que aparecen en los resultados de búsqueda, quedando el buscador obligado a eliminarlos ${ }^{44}$.

En cualquier caso, la Sentencia concretó que el derecho a la protección de datos prevalecerá con carácter general sobre el interés económico del buscador o cualquier

43 La cuestión no es pacífica en la doctrina. Martínez Otero señala algunas dudas razonables al respecto: «Por un lado, resulta dudoso que un buscador sea responsable del tratamiento de datos, en la medida en que es un mero intermediario del contenido, que ni conoce ni valora. Además, en caso de ser responsable, podría acogerse a su derecho a la libertad de empresa y a sus derechos comunicativos, ya que contribuye indudablemente al acceso a la información por parte de los internautas. En este caso, en la medida en que su tratamiento sirve a intereses legítimos, no tiene por qué recabar el consentimiento del afectado. En tercer lugar, encomendarle que como sujeto privado realice la ponderación de los intereses en juego — tratándose de derechos fundamentales — resulta imponerle una potestad arbitral cuestionable, así como una carga de trabajo desproporcionada. Finalmente, también se ha planteado si la resolución del TJUE no estará abriendo la puerta a una censura privada del contenido de la Red, donde el acceso a determinadas informaciones dependerá del juicio de conveniencia realizado por un agente privado» (Martínez Otero, J. M. [2015], «El derecho al olvido en Internet: debates cerrados y cuestiones abiertas tras la STJUE Google vs AEPD y Mario Costeja», en Revista de Derecho Político, n. ${ }^{\circ}$ 92, eneroabril de 2015, p. 138).

44 A raíz de la sentencia del TJUE del 14 de mayo de 2014, Google creó un formulario de contacto para ejercitar el derecho al olvido. Se trata de un formulario largo y detallado, en el que se incluye además de tener que facilitar todos los datos personales y los enlaces polémicos que se quieren retirar, la obligatoriedad de incluir una fotografía escaneada de algún tipo de documento de identidad que se considere suficiente para identificar al responsable de la solicitud. Este formulario, sin embargo, presenta carencias considerables: es «una solución que resulta cuestionable por su restringido alcance. Por un lado, este mecanismo sólo es aplicable a ciudadanos de la Unión Europea - lo que plantea problemas desde el punto de vista del principio de igualdad—, sólo puede solicitarlo el afectado y requiere que se alegue una explicación de las causas que motivan su petición. Por otro lado, aun atendiendo a la demanda presentada por el internauta, el resultado de su petición se ciñe exclusivamente al borrado de los enlaces asociados que no resulten relevantes. Debemos añadir, que este medio implantado para dar respuesta a la demanda ciudadana genera una grave de incertidumbre jurídica en el Derecho español pues el tiempo de respuesta del Comité de expertos con dificultad puede ajustarse al plazo de diez días que establece la Ley de protección de datos y su correspondiente Reglamento de desarrollo. De manera que, en todo caso, el interesado si entendiese que su solicitud no es atendida por Google puede dirigirse a la Agencia Española de Protección de Datos como último recurso» (López Portás, M. ${ }^{a}$ B. [2015], «La configuración jurídica del derecho al olvido en el Derecho español a tenor de la doctrina del TJUE», en Revista de Derecho Político, n. ${ }^{\circ}$ 92, enero-abril de 2015, pp. 172-173). 
tercero, salvo que la información fuera de interés o relevancia pública tal que permitiera justificar su difusión. Es decir, estimó que es indiferente si la información publicada en el pasado fue pública o privada, y consideró que lo relevante es si existe o no un interés legítimo que justifique que esa información reaparezca en la primera página del motor de búsqueda ${ }^{45}$.

Por otro lado, cabe también destacar la STS 545/2015, de 15 de octubre, en la que nuestro alto tribunal se pronunció por primera vez sobre el derecho al olvido digital. Fue una sentencia cuyo interés radicó en ocuparse del derecho de supresión de datos veraces archivados en hemerotecas digitales. Los hechos se remontaban a los años ochenta, cuando dos jóvenes estuvieron implicados en delitos relacionados con tráfico y consumo de drogas; sin embargo, años después, tras cumplir condena por estos hechos y rehacer, en la medida de lo posible, su vida personal, familiar y profesional, comprobaron que, al escribir sus nombres en Google y Yahoo!, lo primero que aparecía era la noticia sobre su detención, ingreso en prisión y padecimiento del síndrome de abstinencia.

Por su parte, la empresa editora del diario y responsable de la hemeroteca no atendió la petición de los procesados de adoptar las medidas necesarias para evitar la difusión actual y permanente de la información publicada cuando sucedieron los hechos $y$, en consecuencia, interpusieron una demanda en protección de su honor, intimidad y su protección de los datos personales. La STS está directamente vinculada con la sentencia europea anteriormente comentada, en la que el Tribunal de Luxemburgo respaldó la retirada de datos por parte del buscador.

La STS 545/2015 entendió que debía respetarse un equilibrio entre la libertad de información que suponen las hemerotecas digitales y los derechos alegados por los demandantes. El Tribunal Supremo estableció que, en los casos en los que las personas carecen de relevancia pública y los hechos que se les atribuyen no tienen interés histórico, es necesario ponderar el potencial ofensivo que para los derechos de la personalidad tiene la información publicada y el interés público en que esa información aparezca vinculada a los datos personales del afectado ${ }^{46}$.

Según el tribunal, la vinculación entre los datos personales de una persona y una información lesiva para su honor e intimidad en una consulta por Internet va perdiendo su justificación, a medida que transcurre el tiempo, si las personas concernidas carecen de relevancia pública y los hechos vinculados a esas personas carecen de interés histórico.

Sin embargo, la Sala rechazó la procedencia de eliminar los nombres y apellidos de la información recogida en la hemeroteca, o de que los datos personales contenidos en la información no pudieran ser indexados por el motor de búsqueda interno del propio diario, ya que consideró que tales medidas supondrían una restricción excesiva de la libertad de información vinculada a la existencia de las hemerotecas

\footnotetext{
${ }^{45}$ Cfr., Simón Castellano, P. (2015). El reconocimiento..., cit., pp. 179 y 183.

${ }^{46}$ Cfr. F. J. 6.
} 
digitales. La sentencia puntualizó que el derecho al olvido digital no ampara que cada uno construya un pasado a su medida —impidiendo la difusión de informaciones sobre hechos que no se consideren positivos - ni justifica que aquellos que se exponen a sí mismos públicamente puedan exigir que se construya un currículo personalizado ${ }^{47}$.

Recientemente ha visto la luz la STC 58/2018, de 4 de junio, en la que nuestro Tribunal Constitucional se ha pronunciado por primera vez sobre el derecho al olvido, precisamente al respecto de un recurso de amparo que interpusieron los demandantes del caso que dio lugar a la STS 545/2015. El TC modifica el criterio del TS, al establecer que «la prohibición de indexar los datos personales, en concreto los nombres y los apellidos de las personas recurrentes, para su uso por el motor de búsqueda interno de El País debe ser limitada, idónea, necesaria y proporcionada al fin de evitar una difusión de la noticia lesiva de los derechos invocados»; y que, si bien es cierto que «la libertad de información constituye no sólo un derecho fundamental de cada persona sino también una garantía de la formación y existencia de una opinión pública libre y plural, capaz de adoptar decisiones políticas a través del ejercicio de los derechos de participación», este derecho no es absoluto, sino que debe ser modulado por dos elementos: uno, el valor del paso del tiempo a la hora de calibrar el impacto de la difusión de una noticia sobre el derecho a la intimidad del titular de ese derecho; y dos, la importancia de la digitalización de los documentos informativos, para facilitar el acceso a la información de todos los usuarios de internet.

La STC explica que en estos casos «podría ponerse en duda la prevalencia del derecho a la información sobre el derecho a la intimidad de una persona que, pasado un lapso de tiempo, opta por solicitar que estos datos e información, que pudieron tener relevancia pública en su día, sean olvidados», y estima que no hay vulneración de las libertades informativas, pues la información no desaparece del diario, aunque sí sea cierto que se dificulta su hallazgo ${ }^{48}$.

La conclusión general a la que se puede llegar, a la vista de todo lo dicho, es que los instrumentos de defensa jurídica de las personas, ante unos datos de su pasado que carecen de interés público pero que le pueden afectar en su trayectoria personal y profesional, se encuentran sobre todo en las agencias de protección de datos. Así, a fin de proteger los derechos de las personas, la experiencia que cabe extraer en España de las resoluciones de estas autoridades reguladoras, pone de manifiesto la importancia que tiene el cumplimiento de algunos criterios como, por ejemplo, la veracidad e interés público de los datos, así como su misma relevancia en tanto que entidades de control y protección del ciudadano como titular de datos especialmente sensibles.

\footnotetext{
47 Cfr. Ibidem.

${ }^{48}$ Cfr. STC 58/2018, de 4 de junio, F. J. 8.
} 


\subsection{El derecho al olvido y las redes sociales}

Respecto a las redes sociales, es difícil no coincidir con Simón Castellano cuando previene del enorme peligro real que suponen, pues, aunque los derechos de oposición, cancelación o rectificación puedan ser eficaces, la información que se pretende eliminar ha estado presente en la red durante un tiempo, el suficiente para poder haber sido descargada y difundida por otros usuarios. En este sentido, se hace fundamental la labor pedagógica de las propias redes sociales (mediante, por ejemplo, la facilitación del acceso a versiones resumidas pero claras de sus políticas de privacidad, adaptadas a un lenguaje accesible para la ciudadanía ${ }^{49}$ ) o de agentes externos a ellas, como la iniciativa «Plan Contigo», por la cual la Policía Nacional y la Guardia Civil aconsejó a jóvenes sobre una gestión adecuada de las opciones de privacidad de la ya extinta red social Tuenti ${ }^{50}$.

Además, en esta misma línea garantista, el artículo 12, in fine, del Real Decreto 1720/2007, de 21 de diciembre, por el que se aprobó el Reglamento de desarrollo de la Ley Orgánica 15/1999, establecía que «corresponderá al responsable del tratamiento la prueba de la existencia del consentimiento del afectado por cualquier medio de prueba admisible en derecho». Una solución lógica, sobre todo si consideramos que en la mayor parte de las ocasiones serán los propios usuarios, sobre todo los menores de edad, los que, desde el desconocimiento acerca de los riesgos y peligros que entraña la prestación del consentimiento en las redes sociales, y apreciando únicamente las ventajas que supone el acceso rápido a la información suministrada e intercambiada en ellas, proporcionarán una edad falsa si lo creen necesario.

Por todo lo dicho, el cumplimiento efectivo del deber de información en la recogida de datos incluye que aquella se facilite de manera comprensible, incluso para los menores de edad, como titulares de dichos datos potencialmente objeto de tratamiento en Internet por parte de los titulares de dominios web y en las redes sociales. La elaboración de versiones fácilmente accesibles y comprensibles de las políticas de privacidad de las redes sociales es un ejercicio de buena praxis y de prevención de futuros posibles incidentes, en el sentido de lo que se ha señalado anteriormente sobre la necesidad de concienciación ciudadana.

Es de igual modo reseñable el acuerdo que se llevó a cabo, en 2009, en Luxemburgo, por la Comisión Europea con 17 de las empresas más importantes de Internet, con el objeto de mejorar la seguridad de los menores de edad ante las redes sociales. Entre los firmantes se encontraban Arto, Bebo, Dailymotion, Facebook, Giovani.it, Google/YouTube, Hyves, Microsoft Europe, Myspace, Nasza-klaza.pl, Netlog, One. lt, Skyrock, StudiVZ, Sulake/Habbo Hotel, Yahoo! Europe, y Zap.lu. Entre las medi-

${ }_{49}$ Elevado al rango de deber para los responsables del tratamiento de datos por los arts. 7.2 y 12 RGPD.

${ }^{50}$ Simón Castellano, P. (2011). «El régimen constitucional del derecho al olvido en Internet», en Neutralidad de la Red y otros retos para el futuro de Internet. Actas del VII Congreso Internacional Internet, Derecho y Política, Barcelona, Huygens Editorial, p. 402. 
das a adoptar, se acordaron las siguientes: proporcionar un botón de «denuncia de abusos» fácil de utilizar y accesible, que permita a los usuarios denunciar, con un solo clic, contactos o comportamientos inadecuados de otros usuarios; asegurarse de que todos los perfiles y listas de contactos en línea de los usuarios de los sitios web registrados como menores de 18 años estén predeterminados como "privados», lo cual hará que a las personas con malas intenciones les resulte más difícil ponerse en contacto con los jóvenes; asegurarse de que los perfiles privados de los usuarios menores de 18 años no puedan buscarse (ni en los sitios web ni a través de motores de búsqueda); garantizar que las opciones de privacidad estén destacadas y sean accesibles en todo momento, de manera que los usuarios puedan averiguar fácilmente quién puede ver lo que cuelgan en línea: si sólo sus amigos o todo el mundo; impedir que los menores de edad utilicen sus servicios: si una red social está dirigida a adolescentes de más de 13 años, a los menores de esa edad debe resultarles difícil registrarse ${ }^{51}$.

En consonancia con estas medidas, cabría añadir las recomendaciones que, en 2013, publicó la AEPD, relativas a las redes sociales. La novedad que presentan es que van dirigidas, no ya a las redes, sino a los usuarios: no etiquetar contenidos audiovisuales con la identidad real de sus protagonistas ni ofrezca datos de terceros en su espacio sin su consentimiento; revisar y leer las condiciones generales de uso y la política de privacidad de la red social en el momento de registrarse; ejercer sus derechos de acceso a los datos que utilice el portal y el derecho de cancelación, o el de cancelar la suscripción cuando se verifiquen cambios en las condiciones legales y políticas de privacidad con los que no se esté de acuerdo; configurar adecuadamente el grado de privacidad del perfil de usuario en la red social, optando por el que resulte más conveniente; aceptar únicamente a aquellas personas conocidas o con las que se mantiene alguna relación previa y no publicar en el perfil información de contacto que permita ubicarnos físicamente; emplear diferentes nombres de usuario y contraseñas para entrar en las distintas redes sociales; y utilizar contraseñas de ocho caracteres o más utilizando tanto letras como números, mayúsculas y minúsculas, así como tener un buen sistema antivirus debidamente actualizado ${ }^{52}$.

Más allá de estas consideraciones, referidas a las necesarias garantías destinadas a preservar los bienes jurídicos de los usuarios de las redes sociales, es preciso recordar que, cuando es el propio usuario el que publica la información en la red social o da su consentimiento inequívoco para que lo haga un tercero, es él el que, al menos en teoría, mantiene en todo caso el control sobre ellos, de tal manera que el responsable del tratamiento debe acceder a eliminar todos aquellos respecto de los cuales se pro2018).

${ }^{51}$ Cfr. http://europa.eu/rapid/press-release_IP-09-232_es.htm (última consulta el 3 de mayo de

52 Las recomendaciones se encuentran en http://www.agpd.es/portalwebAGPD/ canaldocumentacion/publicaciones/common/pdfs/guia_recomendaciones_Internet_052009.pdf (última consulta el 23 de mayo de 2018), y no sólo se refieren a redes sociales o web 2.0, sino igualmente a otros servicios de Internet, tales como buscadores, servicios de navegación, correo electrónico, servicios peer to peer, videocámaras o telefonía IP. 
duce una revocación del permiso. En estos casos, con base en el principio de consentimiento, nadie debe resignarse a que sus datos personales sean incorporados en ficheros, incluso cuando el afectado lo toleró o propició en un momento inicial, pues una de las características del consentimiento, en el ámbito de la protección de datos, es que éste es revocable, ya que de otra manera no sería viable que el titular de los datos tuviera un control efectivo sobre ellos ${ }^{53}$. Por su parte, dispone el art. 7.3 RGPD que el interesado tendrá derecho a retirar su consentimiento en cualquier momento, no afectando a la licitud del tratamiento basado en el consentimiento previo a su retirada.

Algo distinto sucede cuando los datos personales son publicados por un tercero sin el consentimiento inequívoco del afectado. En estos casos de publicación de imágenes, vídeos y textos que contengan datos personales y que puedan lesionar el libre desarrollo de la personalidad, parece evidente que el afectado que no ha prestado su consentimiento podría, amparándose en la normativa sobre protección datos, ejercer el derecho de supresión del art. 17 RGPD o el de rectificación del art. 16 RGPD.

No obstante, se plantea aquí el problema de si ese tratamiento de datos está sujeto a la normativa en esta materia o si, por el contrario, está excluido del régimen de protección de datos personales, al ser considerados ficheros mantenidos por personas físicas en el ejercicio de actividades exclusivamente personales o domésticas ${ }^{54}$. Esta exclusión de aplicabilidad, conocida como excepción doméstica, implica que, cuando los datos de otro sujeto son objeto de tratamiento en el seno de las relaciones mantenidas dentro de la esfera familiar o de amistad, no es necesario recabar el consentimiento. Publicar datos personales de otro en un perfil propio, en el contexto de una red social, no cae, en principio, en este ámbito de la excepción doméstica. En este sentido se pronunció el TJUE en el asunto Lindqvist ${ }^{55}$. De esta forma, la difusión de datos personales a través de las redes sociales está sujeta a la normativa de protección de datos, porque, por regla general, dichos datos son accesibles a una pluralidad indeterminada de personas, y de ahí que se precise un consentimiento inequívoco. Sin embargo, si el espacio de la red social se configura como cerrado y solo accesible a un número determinado de personas, puede sostenerse que el tratamiento de datos que se puede efectuar en este ámbito se inscribe dentro de la esfera personal del individuo y, por lo tanto, no está sujeto a la legislación de protección de datos ${ }^{56}$.

53 Simón Castellano, P. (2015). El reconocimiento..., cit., p. 312.

54 Así lo dispone el art. 2.2. a) LOPD, que se remite al art. 2.2 RGPD, que señala que no será de aplicación al tratamiento de datos personales «efectuado por una persona física en el ejercicio de actividades exclusivamente personales o domésticas».

55 STJUE de 6 de noviembre de 2003, par. 47: «Esta excepción debe interpretarse en el sentido de que contempla únicamente las actividades que se inscriben en el marco de la vida privada o familiar de los particulares; evidentemente, no es este el caso de un tratamiento de datos consistente en la difusión de dichos datos por Internet de modo que resulten accesibles a un grupo indeterminado de personas».

56 Cfr. Mieres Mieres L. J. (2014). El derecho..., cit., p. 49. 
A la vista de estos riesgos planteados por el uso descontrolado de las redes sociales, fueron numerosos los esfuerzos realizados por la Comisión Europea para introducir un derecho al olvido que permitiera a los sujetos estar más protegidos ante ellas. Así lo expresó la vicepresidenta de la Comisión Europea, Viviane Reding: «Al modernizar la legislación, quiero clarificar específicamente que las personas deben tener el derecho, y no sólo la posibilidad, de retirar su consentimiento al procesamiento de datos. Por ello, el primer pilar de la reforma será el «derecho a ser olvidado»: un conjunto completo de reglas nuevas y existentes para afrontar mejor los riesgos para la privacidad en Internet ${ }^{57}$.

La entrada en vigor del RGPD también ha supuesto la posibilidad de garantizar el principio de privacidad a través del diseño y de la privacy by default, que implican que la protección de la intimidad, de la reputación y de los datos personales de los individuos se tiene en cuenta a lo largo de todo el ciclo de vida de las tecnologías, desde su concepción hasta su despliegue, utilización y eliminación final, es decir, que los datos de los usuarios no podrán hacerse públicos salvo que los usuarios hubieran dado su permiso expreso.

Cualquier medida garantista en el ámbito de las redes sociales es tan necesaria como, sin embargo y a nuestro juicio, insuficiente. En el capítulo siguiente, dedicado a las conclusiones, intentaremos ofrecer una visión crítica de todo lo expuesto hasta ahora, con especial consideración hacia la tendencia, tan característica de nuestra cultura, a confiar desmedidamente al Derecho y sus normas la función de garantes del bienestar ciudadano y de la ausencia de conflictos.

\section{ALGUNAS CONCLUSIONES}

Cuando salió a la luz el escándalo de Cambridge Analytica ${ }^{58}$, desde diversas instancias se llegó a proponer una campaña de sabotaje a Facebook, por haber dado lugar a la proliferación de fake news que habrían llegado a propiciar el ascenso al poder de Donald Trump. El propio cofundador de WhatsApp (empresa adquirida por la compañía de Zuckerberg en 2014), Brian Acton, llegó a afirmar en Twitter que había «llegado el momento» de abandonar Facebook ${ }^{59}$. El descenso de usuarios, sin embargo, apenas se notó.

La anécdota bien nos sirve para subrayar algo que guarda una estrecha relación con la configuración de los derechos que garantizan la privacidad o la dignidad de los

57 Vid. Bruselas garantizará por ley el «derecho al olvido» en redes sociales como Facebook, en http://www. europapress.es/portaltic/sector/noticia-bruselas-garantizara-ley-derecho-olvido-redes-socialesfacebook-20110316184134.html (última consulta el 23 de mayo de 2018).

58 Puede consultarse el caso en https:/elpais.com/tag/caso_cambridge_analytica/a (última consulta el 25 de mayo de 2018).

59 En https://twitter.com/brianacton/status/976231995846963201?s=21 (última consulta el 24 de mayo de 2018). 
usuarios de Internet: la verdad es que, a juzgar por los datos y estadísticas, la propia Internet ha resultado ser una entidad jurídicamente anárquica, potencialmente lesiva, $\mathrm{y}$, pese a todo, incondicionalmente merecedora de la inquebrantable lealtad de aquellos mismos ciudadanos que, con frecuencia, claman y reclaman contra ella.

Es obvio - así nos lo enseñaron nuestros maestros en las Facultades de Derechoque la realidad precede a la norma, y que la ley se ocupa de regular las posibles situaciones de conflicto que pudieran originarse. En Internet, sin embargo, esta máxima se modula. En efecto, Internet es previo a su propia regulación legal, pero, además, la fluidez de la red es tal que resulta muy difícil, en ocasiones, ofrecer una definición precisa de lo que Internet es, y no son infrecuentes las veces en las que mezclamos lo que es con lo que fue o con lo que esperamos que sea. El resultado es que, si la realidad de Internet no es clara (porque sus contornos son difusos y cambian casi a la misma velocidad que los deseos y expectativas que los usuarios proyectan sobre ella), los derechos que la regulen están condenados a la perentoriedad, a un ejercicio errático y a una eficacia cuestionable.

El derecho al olvido es una de esas construcciones que nacieron hace no demasiado tiempo con una pretensión loable: contribuir a que los usuarios de Internet pudieran controlar el destino de los datos personales que diariamente vierten en el sinfín de aplicaciones y páginas web que visitan o manejan, o que son objeto de tratamiento sin que concurra su consentimiento. De tal manera, la función del derecho al olvido estaría relacionada con preservar a la ciudadanía de potenciales lesiones relativas a bienes jurídicos relacionados con su dignidad o su intimidad.

Sin embargo, a día de hoy, Internet ha sabido establecer una conexión profunda con los deseos y pulsiones de unos individuos que ya no saben ni pueden entenderse sin ella, y, además, está provocando cambios biosociales profundos ${ }^{60}$ a una velocidad inédita hasta la fecha.

Es, sin duda, una decisiva baza con la que cuenta Internet —y su ilimitada oferta de posibilidades, diversión, emociones y entretenimiento, todo en un contexto donde prima la inmediatez - frente al Derecho, percibido en estos tiempos como un tedioso e ininteligible entramado de normas emanadas de un conjunto de representantes continuamente cuestionados por escándalos que afectan a su vida pública o privada, e interpretadas por un poder judicial y unos expertos en Derecho que también anteponen sus intereses particulares a la propia impartición de Justicia.

Se trate o no de una visión demasiado exagerada, lo que consideramos que no ofrece ninguna duda es que Internet cuenta con la complicidad, de inicio acrítica, de la mayoría de sus usuarios. Esto supone un problema cuando son esos mismos usuarios los que, tras experimentar en sí mismos los nocivos efectos de virtualizar demasiado

${ }^{60}$ Vid. Harari, Y. N. (2016). Homo Deus, cit. Nos referimos sobre todo a la obra de Harari por considerar que es el autor que de forma más sistemática y rigurosa ha abordado la cuestión del cambio de paradigma digital, pero no es el único. A los estudios antropológicos habría que unir los científicos, encaminados algunos de ellos a potenciar el uso de implantes digitales que reconfiguren nuestra visión o relación con la realidad que nos rodea (fenómeno que se conoce como biohacking). 
su propia identidad personal, de volcar datos de forma inconsciente, o de asumir riesgos en red, deciden enfrentarse a la misma realidad a la que hasta justo entonces se habían entregado sin los miramientos ni las cautelas necesarias ${ }^{61}$.

De vuelta al ejemplo que abrió este capítulo, tras la inicial indignación de un amplio sector ciudadano por el robo de datos que pudo ayudar al denostado Trump en su ascenso al poder, sucedió lo esperable: el culpable, Facebook, era ya uno de los nuestros, así que una ínfima parte de esos ciudadanos fueron capaces de plantarle cara. Este síndrome de Estocolmo 2.0 convierte en representaciones paródicas muchas de las campañas de prevención y muchas medidas de resolución de conflictos relacionados con Internet y con las tecnologías afines a ella ${ }^{62}$.

Para comenzar a hablar con fundamento del derecho a la supresión de datos personales es necesario articular todo un aparato normativo que le dé cobertura, así como medios técnicos suficientes que permitan su implantación real. Contamos con unos y con otros y, en ese sentido, el derecho al olvido es un éxito. Pero para que la finalidad con la que se pensó el derecho al olvido se alcance es imprescindible, además, un posicionamiento crítico frente a Internet, del que, a día de hoy, por lo general carecemos.

Los padres preocupados por el uso que sus hijos den a las nuevas tecnologías son muchas veces los mismos que no les han querido preservar de ellas desde que aún eran niños; las escuelas que invitan a expertos a que hablen a sus alumnos de los riesgos de Internet son las mismas que destinan partidas presupuestarias a la compra masiva de tablets para esos mismos alumnos; los usuarios que reclaman hoy el respeto a su intimidad son los mismos que vertían ayer datos íntimos en aplicaciones cuyo funcionamiento en cuanto al tratamiento de datos no han querido deliberadamente conocer.

Una de las particularidades de pensar y de hablar sobre derecho al olvido es que sirve casi como paradigma de una sociedad compuesta por individuos cuyos intereses y conductas transitan en sentidos opuestos. Esto es algo que se entiende muy bien cuando nos referimos a los menores de edad, a los nativos digitales de los que tanto se habla, desde esa mezcla entre precaución, de una parte, y, de otra, rendida admiración que nos suscita hoy todo lo relacionado con el particular mundo de la infancia. El interés superior del menor es una máxima que impregna casi la totalidad de la normativa que, directa o tangencialmente, hace referencia a los menores de edad. Y, sin embargo, si nos preguntásemos en qué consiste la defensa de dicho interés, no encontraríamos una respuesta, no ya unánime, sino mínimamente coherente, pues no

${ }^{61}$ La pregunta ya se ha convertido en tópica, pero ¿qué usuario de Internet dedica hoy tiempo a leer y estudiar los términos y condiciones de uso de los servicios que se le ofrecen y que van a afectar al tratamiento de sus datos personales? Sobre esa pregunta construye la profesora Arenas Ramiro un excelente trabajo: Arenas Ramiro, M. (2013). «Hacia un futuro derecho al olvido de ámbito europeo», en Valero Torrijos, J. (coord.), La protección de datos personales en Internet ante la innovación tecnológica: riesgos, amenazas y respuestas desde la perspectiva jurídica, Pamplona, Thomson Reuters-Aranzadi, pp. 325-380.

${ }_{62} \mathrm{Al}$ respecto, vid. El efecto red y por qué te cuesta tanto dejar Facebook, en https://verne.elpais.com/ verne/2018/04/17/articulo/1523972987_879831.html (última consulta el 28 de mayo de 2018). 
está resuelta —ni a nivel teórico— la tensión entre dos polos opuestos: preservarles de determinados contenidos o respetar su libertad, de facto irrestricta, en el uso de las nuevas tecnologías ${ }^{63}$.

El RGPD, en este escenario, comparece como una herramienta bienintencionada tendente a elevar el nivel de garantía y control de los ciudadanos sobre el destino de sus propios datos. Para ello, positiviza por primera vez el derecho al olvido, y lo rodea de otros derechos e instrumentos con esa misma finalidad compartida (el establecimiento de la privacy by design y by default, el incremento en las medidas de transparencia, el derecho a la portabilidad de los datos, la creación de la figura del delegado de protección de datos, el refuerzo del consentimiento...). Confiamos en que la nueva norma europea y aquellas otras de Derecho interno a las que ha dado y dará lugar no escollen en unos malos hábitos sociales que son tantas veces incompatibles con el respeto de datos personales propios o de terceros.

Algo similar cabría decir de la encomiable labor que lleva a cabo la AEPD en su tarea de defender a los usuarios de los abusos que pudieran sufrir como consecuencia de abusos de los diversos operadores de Internet. La tarea de velar por el cumplimiento de la normativa de protección de datos encuentra, en nuestros días, la paradójica dificultad de tener que pugnar con unos ciudadanos cuyo comportamiento en la red podría llevarnos a pensar que asumen el daño cuya reparación exigen.

Se nos podría achacar que, en otros tiempos, nunca han faltado profetas de calamidades para los grandes cambios de la humanidad. Sin embargo, no creo que ningún otro punto de inflexión propio en nuestra historia sea comparable ni tenga el alcance que Internet está presentando. El nuevo paradigma trasciende lo jurídico para adentrarse en la misma autoconsciencia humana. Lógicamente, esas consideraciones están fuera de los límites de este trabajo, pero cada día son más los estudios que profundizan en la cuestión desde los distintos enfoques que ofrecen las ciencias sociales y las experimentales.

${ }^{63}$ No sólo podríamos volver a traer a colación la encuesta de la que se hicieron eco algunos medios de comunicación, a la que ya nos referimos supra, en nota 15. Fijémonos también en el RGPD: entre las muchas remisiones que hace a las matizaciones que pudieran introducir los estados miembros en sus respectivas legislaciones se encuentra la contemplada en su art. 6.1: «[...] Si el niño es menor de 16 años, tal tratamiento únicamente se considerará lícito si el consentimiento lo dio o autorizó el titular de la patria potestad o tutela sobre el niño, y sólo en la medida en que se dio o autorizó. Los Estados miembros podrán establecer por ley una edad inferior a tales fines, siempre que esta no sea inferior a 13 años». Nuestra LOPD sitúa la edad de consentimiento válido para la cesión de datos a terceros en 14 años (art. 7.1). Por lo tanto, menor que la exigida por la normativa europea. Más aún: para Facebook, la edad mínima para abrirse una cuenta es 13 años. ¿Cómo ha podido compaginarse esa previsión con la normativa europea y la española? Pensemos en las declaraciones que hace algunos años realizaba Mozelle Thompson, responsable de privacidad de Facebook, cuando afirmaba que diariamente se suprimen más de 20.000 perfiles diarios debido a falsificaciones de datos en el registro de las cuentas (puede verse la noticia, por ejemplo, en http://www.abc.es/20110325/medios-redes/abci-facebook-eliminacion-perfilesdiarios-201103251339.html, última consulta el 24 de mayo de 2018). 
Podrá objetarse también a estas conclusiones que trazan un sombrío panorama, porque nos sitúan, una vez más, frente a una sociedad inconsciente que entroniza las causas a la vez que condena las consecuencias. A ello se le une el ya aludido desdén generalizado hacia las normas jurídicas y las instancias que las producen y aplican. El resultado no es halagüeño, pero sólo con un certero análisis global ${ }^{64}$, desde las distintas disciplinas afectadas, se podrá contribuir a que las nuevas tecnologías y el derecho que regula su ejercicio estén realmente al servicio de una sociedad de hombres y mujeres libres que aprendan a no anteponer su seguridad o su comodidad a su propia e irrenunciable dignidad.

\section{BIBLIOGRAFÍA}

Agencia de Seguridad de las Redes y de la Información de la Unión Europea (ENISA), Propuesta "The right to be forgotten - between expectations and practise», de 18 de octubre de 2012.

Álvarez Caro, M., Derecho al olvido en Internet: el nuevo paradigma de la privacidad en la era digital, Reus, Madrid, 2015.

Álvarez CARo, M., «El derecho a la supresión o al olvido», en Piñar Mañas, J. L., Reglamento europeo de protección de datos. Hacia un nuevo modelo europeo de privacidad, Editorial Reus, Madrid, 2016.

Arenas Ramiro, M., «Hacia un futuro derecho al olvido de ámbito europeo», en VAlero Torrijos, J. (coord.), La protección de datos personales en Internet ante la innovación tecnológica: riesgos, amenazas y respuestas desde la perspectiva jurídica, Thomson Reuters-Aranzadi, Pamplona, 2013.

Azurmendi, A., «Por un «derecho al olvido» para los europeos: aportaciones jurisprudenciales de la Sentencia del Tribunal de Justicia europeo del caso Google Spain y su recepción por la Sentencia de la Audiencia Nacional española de 29 de diciembre de 2014», en Revista de Derecho Político, n. ${ }^{\circ}$ 92, enero-abril de 2015, pp. 273-310.

Bauman, Z. y Lyon, D., Vigilancia líquida, Paidós, Barcelona, 2013.

Bauman, Z., Vida líquida, Paidós, 2010, Barcelona.

Berrocal Lanzarot, A. I., Derecho de supresión de datos o derecho al olvido, Reus, Madrid, 2017.

Borges, J. L., Ficciones, Alianza Editorial, Madrid, 2006.

64 Álvarez Caro se refiere a esta misma necesidad, pero únicamente para abogar por la compaginación de la perspectiva jurídica con la económica, fruto de los intereses empresariales de agentes comerciales provenientes de países con diversas tradiciones jurídicas (en Álvarez Caro, M. (2015). Derecho al olvido en Internet: el nuevo paradigma de la privacidad en la era digital, Madrid, Editorial Reus, pp. 131 y 132). Nosotros asumimos esa globalidad, pero consideramos que han de aunarse esfuerzos y conocimientos propios de otras ciencias. Un cambio verdaderamente global requiere una respuesta del mismo tipo. 
CARr, R., ¿Qué está haciendo Internet con nuestras mentes? Superficiales, Taurus, Barcelona, 2017.

CoвAcho López, Á., «La ponderación de bienes en los conflictos jurídicos relacionados con internet: el derecho al olvido», Desafíos para los derechos de la persona ante el siglo XXI: internet y nuevas tecnologías, Pamplona, Aranzadi, 2013, pp. 145-152.

Cobacho López, Á., «Autodeterminación informativa de los menores II», en PÉrez Álvarez, S., Burguera Ameave, L. y Paul Larrañaga, K., Menores e Internet, Thomson-Reuters Aranzadi, Pamplona, 2013.

Cobacho López, Á. y Burguera Ameave, L., «El derecho al olvido de los políticos en las campañas electorales», en Corredoira y Alfonso, L. y Cotino Hueso, L., Libertad de expresión e información en Internet, Centro de Estudios Políticos y Constitucionales, Madrid, 2013, pp. 101-120.

Crespo Vitorique, I., «El nuevo reglamento de protección de datos, ¿hacia dónde ir?: decálogo de los principales aspectos que tener en cuenta», en Análisis GAEP, mayo 2016.

De Terwagne, C., «Privacidad en Internet y el derecho a ser olvidado/derecho al olvido», en Revista de Internet, Derecho y Política, núm. 13, 2012.

DiÉGuez, A., Transhumanismo. La búsqueda tecnológica del mejoramiento bumano, Herder, Barcelona, 2017.

Gomes de Andrade, N. N., «El olvido: El derecho a ser diferente... de uno mismo. Una reconsideración del derecho a ser olvidado», en Revista de Internet, Derecho y Política, núm. 13, 2012.

HaN, B.-CH., La sociedad de la transparencia, Herder, Barcelona, 2013.

Han, B.-CH., Psicopolítica, Herder, Barcelona, 2014.

Harari, Y. N., Homo Deus. Breve Historia del mañana, Debate, Barcelona, 2016.

López Álvarez, L. F., Protección de datos personales: adaptaciones necesarias al nuevo Reglamento europeo, Francis Lefebvre, Madrid, 2016.

López Portás, M. ${ }^{a}$ B., «La configuración jurídica del derecho al olvido en el Derecho español a tenor de la doctrina del TJUE», en Revista de Derecho Político, n. ${ }^{\circ}$ 92, enero-abril de 2015, pp. 143-175.

Marín Pedreño, H., Teoría de la cordura y de los hábitos del corazón, Pre-Textos, Valencia, 2010.

Martínez Otero, J. M., «El derecho al olvido en Internet: debates cerrados y cuestiones abiertas tras la STJUE Google vs AEPD y Mario Costeja», en Revista de Derecho Político, n. ${ }^{\circ}$ 92, enero-abril de 2015, pp. 103-142.

Mayer-Schönberger, V., Delete: The Virtue of forgetting in the Digital Age, Princeton University Press, Princeton, 2009.

Mieres Mieres, L. J., El derecho al olvido digital, Iosu Latorre, Madrid, 2014.

Noval Lamas, J., «Algunas consideraciones sobre la futura regulación del derecho al olvido», en Revista de Contratación Electrónica, núm. 9, 2012.

OrZa LinARES, R. M., «El derecho al olvido en Internet: algunos intentos para su regulación legal», en Corredoira y Alfonso, L. y Cotino Hueso, L., Liber- 
tad de expresión e información en Internet, Centro de Estudios Políticos y Constitucionales, Madrid, 2013, pp. 478-487.

SANZ LARRUGA, F. J., «El derecho ante las nuevas tecnologías de la información», en Anuario da Facultade de Direito da Universidade da Coruña, núm. 1, 1997.

Simón Castellano, P., «El derecho al olvido en el universo 2.0», en Textos universitaris de biblioteconomia i documentació, núm. 28, Barcelona, 2012.

Simón Castellano, P., El reconocimiento del derecho al olvido digital en España y en la UE. Efectos tras la sentencia del TJUE de mayo de 2014, Bosch, Barcelona, 2015.

Simón Castellano, P., El régimen constitucional del derecho al olvido, Tirant Lo Blanch, Valencia, 2012.

Simón Castellano, P., «El régimen constitucional del derecho al olvido en Internet», en Neutralidad de la Red y otros retos para el futuro de Internet. Actas del VII Congreso Internacional Internet, Derecho y Política, Universitat Oberta de Catalunya, Huygens Editorial, Barcelona, 2011.

Spitzer, M., Demencia digit@l, Ediciones B, Barcelona, 2013.

Touriño, A., El derecho al olvido y a la intimidad en Internet, Catarata, Madrid, 2014.

Title:

Some reflections on the last update of the right to be forgotten

\section{Summary:}

1. Introduction: The Exercise of Fundamental Rights in the Technological Era. 2. The Right to be Forgotten in Spanish Law and in the New Community Framework. 2.1. The Legal Framework of the Right to Oblivion. 2.2. La Aepd y el derecho al olvido. 3. The Various Fields of Application of the Right to be Forgotten. 3.1. The Right to be Forgotten and the Search Engines and Digital Newspaper Libraries. 3.2. The Right to be Forgotten and the Social Networks. 4. Conclusions. 5. Bibliography.

\section{Resumen:}

Hablar de la irrupción de Internet como detonante de una serie de cambios profundos en nuestra cultura jurídica se ha convertido ya en un lugar común para este tipo de trabajos de investigación. No obstante, debido a la inherente fluidez de los servicios y prestaciones que la red ofrece, es necesario profundizar en los efectos que las nuevas tecnologías han provocado en la configuración de nuestros derechos fundamentales y de nuestras instituciones jurídicas y políticas. 
Junto con la necesaria puesta al día de las formas de ejercicio de los derechos fundamentales reconocidos por nuestra Constitución, Internet ha conllevado la creación de derechos nuevos que, si bien encuentran su fundamento en derechos preexistentes, suponen una adaptación de construcciones clásicas a los requerimientos de los nuevos tiempos. Entre ellos, ocupa un lugar preeminente el derecho al olvido, por la cantidad de estudios a que ha dado lugar y por el reciente reconocimiento expreso en el Reglamento General de Protección de Datos a nivel europeo.

Dicha norma ha supuesto la derogación de la Directiva Europea 95/46/ CE del Parlamento Europeo y del Consejo, de 24 de octubre de 1995 y la promulgación de la nueva Ley Orgánica 3/2018, de 5 de diciembre, de Protección de Datos Personales y garantía de los derechos digitales. Pese a los numerosos interrogantes que todavía plantea la interpretación y aplicación de sus muchos preceptos, se trata del primer texto legal directamente aplicable en España que se refiere por su nombre al derecho al olvido, entendido como esa pretensión de muchos usuarios de Internet de que sus datos sean retirados de la vista y escrutinio público, con independencia de que su tratamiento haya sido o no consentido.

Este trabajo se ocupará del análisis de este nuevo derecho de supresión de datos a la luz de las actualizaciones más recientes en su régimen jurídico, tras la entrada en vigor de dicho Reglamento y algunos pronunciamientos de tribunales comunitarios y nacionales, que van contribuyendo a dotarlo de perfiles cada vez más nítidos.

De lo que no cabe duda alguna es de que, frente a Internet, erigido en factor que está suponiendo un cambio integral de paradigma, no sólo jurídico, sino global, la respuesta ofrecida desde el Derecho no puede prescindir de un enfoque lo más amplio posible, con la finalidad de ofrecer soluciones satisfactorias a los ciudadanos para el creciente número de situaciones de riesgo a las que se enfrentan diariamente, y de prever los conflictos que puedan ocasionarse en el futuro.

\section{Abstract:}

Talking about the irruption of the Internet as a trigger for a series of profound changes in our legal culture has already become a common place for this kind of research works. However, due to the inherent fluidity of the apps and services offered by the network, it has become necessary to take a close look at the effects that new technologies have caused in the configuration of our fundamental rights and our legal and political institutions. Along with the necessary updating of the forms of exercise of fundamental rights recognized by our Constitution, the Internet has led to the creation of new rights that, although they are based on pre-existing rights, involve an adaptation of classic constructions to the requirements of the new times. Among them, the right to be forgotten has a pre-eminent place, due to the number of studies it has caused and to the recent express recognition in the General Regulation of Data Protection, at European level. 
This Regulation has led to the repeal of the European Directive 95/46 / EC of the European Parliament and of the Council, of October 24, 1995, and the enactment of the new Organic Law 3/2018, of December 5, about protection of personal data and guarantee of digital rights. Despite the many questions that the interpretation and application of its many precepts still lay out, it is the first legal text directly applicable in Spain that refers by its name to the right to be forgotten, understood as the pretense of many Internet users that their data are removed from public view and scrutiny, regardless of whether or not their treatment has been consented. This work will deal with an analysis of this new right of supression of data taking into account the most recent updates in its legal regime, after the entry into force of this Regulation and some pronouncements of Community and national courts, which are contributing to equip it of increasingly clear profiles.

There is no doubt that, regarding the Internet, erected as a factor that is assuming an integral change of paradigm, not only legal, but also global, the response offered by Law can not manage without an as wide as possible approach, in order to offer satisfactory solutions to citizens for the growing number of risk situations they daily face, and to anticipate conflicts that may arise in the future.

\section{Palabras clave:}

Internet; derecho al olvido; protección de datos; reglamento; privacidad.

\section{Key words:}

Internet; right to be forgotten; data protection; regulation; privacy. 